\title{
PREPARATION OF SPHERICAL POLYMERIC PARTICLES FROM TANZANIAN CASHEW NUT SHELL LIQUID BY SUSPENSION POLYMERIZATION
}

\author{
LL Mkayula, YMM Makame and TH Matechi \\ Department of Chemistry, University of Dar es Salaam, \\ P.O. Box 35061, Dar es Salaam, Tanzania
}

Accepted 04 March 2004

\begin{abstract}
Spherical Polymeric Particles (SPP) have been prepared from Tanzanian Cashew Nut Shell Liquid (CNSL) by suspension polymerization technique involving either step-growth or chaingrowth polymerization mechanisms. The sizes of the SPP, which ranged from 0.1 to $2.0 \mathrm{~mm}$ were strongly influenced by the amounts of stabilizers in polymerization recipes used. The particles showed variable surface areas, indicative of the presence of pores in some of the preparations and the highest surface area recorded was about $260 \mathrm{~m}^{2} \mathrm{~g}^{\mathrm{l}}{ }^{\mathrm{I}}$. The particles were found to exhibit Langmuir-type adsorption isotherms with saturation capacity of about 9.0 and $44.2 \mathrm{mg} / \mathrm{g}$ for $\mathrm{Na}^{+}$and $\mathrm{Ca}^{2+}$, respectively. Step-growth polymerization produced SPP with relatively smaller surface areas and lower adsorption capacities of sodium and calcium ions compared to the particles produced through the chain-growth mechanism. Other particle characteristics depended strongly on the recipe employed and the surface $O H$ functional groups apparently determine the potential applications of the SPP.
\end{abstract}

\section{INTRODUCTION}

Preparation of spherical polymeric particles by suspension polymerization technique is well documented (Mark et al. 1989, Ahmed 1984, Brooks 1990). The sizes of the polymer particles resulting from suspension polymerization range between about $50 \mu \mathrm{m}$ and $5 \mathrm{~mm}$ hence the term bead or pearl polymerization. Spherical polymeric particles have been used in a wide range of surface-chemical applications, such as support for catalysts (Arshady 1992, Hodge 1980), gel filtration and ion exchange resins (Rolls et al. 1990). These particles are suited for such applications due to their mechanical stability, narrow size distribution and dynamic behavior as well as the ease with which mathematical modeling of chemical processes can be worked out (Mark et al. 1989).

Recently the synthesis of polymers from renewable natural resources has attracted considerable attention of research workers due to escalating prices as well as high rate of depletion of the natural mineral resources (Bhunia et al. 1998, Mwaikambo and Ansell 2001). Cashew Nut Shell Liquid (CNSL) is a natural product whose source is the cashew tree, Anarcardium occidantale Lin, which is a widely grown cash crop in Tanzania and in some neighboring countries. The industrial process of recovering edible kernel from the nuts yields, as a by-product, the technically useful reddish brown CNSL (Anand 1978, Gedam et al. 1986). Chemical analyses of CNSL have established that the liquid consists of a mixture of phenolic compounds having long chains of saturated and unsaturated hydrocarbon substituents and consists of mainly four major components, namely, cardanol (1), cardol (2), 2-methyl cardol (3) and anarcardic acid (4). 
<smiles>Oc1ccccc1</smiles>

1<smiles>Cc1ccccc1O</smiles>

3

$\mathrm{R}=\mathrm{C}_{15} \mathrm{H}_{31-\mathrm{n}}$

$\mathrm{n}=0,2,4$ or 6

Cardanol is present in small amounts in solvent extracted CNSL but it is the major product of thermally extracted CNSL (Tyman 1975).

As a result of the phenolic nature and the presence of the long alkyl chain with a variable degree of unsaturation, the components of CNSL have been subjected to step-growth polymerization or chaingrowth polymerization to yield numerous polymer products for various applications such as surface coating, adhesives, laminating resins, friction resistant components, molding materials, surface active agents, oil and paint additives, and ion-exchange resins or membranes (Anand 1978, Anand 1981, Gedam et al. 1986). The manufacture and application of CNSL based polymers, however, are reported in the patent literature, if not kept as industrial secrets.

Although workers in many industrial laboratories have attempted to polymerize CNSL under different experimental conditions, very little has been reported at on suspension polymerization of the same, to produce surface reactive materials. In this work, suspension polymerization of CNSL and its distillate product cardanol to produce spherical polymeric particles (SPP) and surface characterization of the latter is reported.

\section{EXPERIMENTAL \\ Materials}

Technical CNSL was supplied by TANITA Company Limited based in Dar es Salaam. Pure cardanol was obtained by vacuum distillation of CNSL at $180{ }^{\circ} \mathrm{C}$ and 0.1 $\mathrm{mmHg}$ and its purity was affirmed by TLC. All reagents and solvents were A.R. grade supplied by Aldrich. White spot nitrogen gas and liquid nitrogen were supplied by Tanzania Oxygen limited (TOL).

\section{Preparation of Spherical Polymeric Particles}

Suspension polymerization was carried out in a four-neck jacketed reactor of $1 \mathrm{dm}^{3}$ capacity with water as the dispersion medium and either CNSL or cardanol in the dispersed monomer phase. The reactor was equipped with a glass baffle, a teflon stirrer, a nitrogen gas inlet tube, a thermometer and a J-shaped glass tube for sampling.

For the chain-growth (addition) polymerization of CNSL or cardanol, the predetermined volume of distilled water and the respective amounts of stabilizers (as shown in table 1) were charged into the reactor and the mixture was heated under nitrogen purging. In a separate container, the initiator was dissolved in either the technical CNSL or the freshly distilled cardanol and later added into the reactor after the latter's contents had attained the chosen reaction temperature.

In step-growth (condensation) polymerization of CNSL or cardanol, the reactor was charged with a mixture of distilled water and stabilizers followed by heating under nitrogen purging. A mixture of either CNSL or its distillate and formalin with $2-3 \mathrm{ml}$ of $7 \%$ sodium hydroxide was mixed with the aqueous mixture after the latter had attained the reaction temperature. The exact amounts of ingredients used are shown in table 1. 
Constant temperature and agitation were maintained throughout the period of polymerization. The particles formed were separated from the reaction medium by using basket sieves, washed with plenty of distilled water and dried in a Gallenkamp oven at between 80 and $150{ }^{\circ} \mathrm{C}$ overnight.

\section{Determination of Chemical Stability of the Particle}

The CNSL based spherical polymer particles were treated with different reagents including organic solvents, mineral acids and concentrated alkaline solutions in order to determine their resistance against chemicals and solvents. The particles were soaked in different reagents for 24 to 48 hours and subsequently observed for any change in their physical structures, physico-chemical properties as well as attrition.

\section{Determination of Particle Sizes}

Standard testing sieves (specification E 11 ASTM) were used for particle size analyses. The dried SPP samples were shaken for 20 min by an EML 200 - 67 vibration machine at a vibrating amplitude of 60 .

\section{Determination of Surface Area}

The surface areas of the beads were determined from nitrogen physical adsorption measurements carried out at $77 \mathrm{~K}$ in a static volumetric adsorption system as reported elsewhere (Heal and Mkayula 1988). The surface areas were evaluated from $\mathrm{N}_{2}$ adsorption data using the BET equation (Brunauer et al. 1938).

\section{Determination of Ion Adsorption Capacity}

The ion adsorption capacity of the SPP was determined by batch method as follows: 200 ppm stock solutions of $\mathrm{Na}^{+}$and $\mathrm{Ca}^{2+}$ were prepared by dissolving appropriate amount of a pure carbonate of the respective metals in small amount of dilute hydrochloric acid, followed by dilution with distilled water to the required volume. Less concentrated solutions of sodium and calcium ions were obtained by successive dilution of the stock solutions with distilled water. Samples of polymer beads weighing about $0.1 \mathrm{~g}$ were placed in Erlenmeyer flasks and mixed with solutions of different concentrations of sodium or calcium ions. The flasks were then placed on a batch shaker and shaked at a rate of 130 strokes/min at $25-30{ }^{\circ} \mathrm{C}$ for 24 hours. Thereafter the beads were filtered-off and the concentrations of both the treated and untreated solutions were determined by Atomic Absorption Spectroscopy (AAS). A Perkin-Elmer spectrometer model AA-300 was used.

\section{RESULTS AND DISCUSSION \\ Preparation of SPP}

Vacuum distillation of CNSL gave cardanol fraction of $98 \%$ purity and yield of about $42 \%$. Cardanol was used as a monomer in some of the recipes, in other recipes the technical CNSL was used without further purification. Table 1 shows various successful recipes for preparing SSP. The recipes involved cardanol $(\mathrm{CDN})$, a mixture of styrene and cardanol (SCDN), and technical cashew nut shell liquid (CNSL). The SSP produced were coded in such a way that the abbreviation before a bracket represents the monomer used; the number inside the bracket represented the recipe number; and the abbreviation $\mathrm{C}_{\mathrm{g}} \mathrm{P}$ or $\mathrm{S}_{\mathrm{g}} \mathrm{P}$ after the bracket describes the most likely polymerization mechanism involved in the given recipe. Generally longer reaction times $(12-24 \mathrm{~h})$ were required to obtain SPP by addition (chain) polymerization compared to $6-10 \mathrm{~h}$ needed to get SPP by condensation (step) polymerization under similar conditions of temperature. This difference in rates between the step-growth and chaingrowth polymerization of CNSL or its distillation product, cardanol, is not unexpected and could be attributed to the differences in the kinetics of the reaction mechanisms involved. Though SPP were obtained much faster by step growth mechanism, stabilization of the particles in this case required larger amounts of stabilizers than by chain growth mechanism. 
Table 1: Preparation of spherical polymeric particles - the successful recipes.

\begin{tabular}{|c|c|c|c|c|c|}
\hline \multirow{2}{*}{ Recipe no. } & \multicolumn{4}{|c|}{ Amounts of different ingredients in the recipes } & \multirow{2}{*}{$\begin{array}{l}\text { Reaction } \\
\text { Temp. }\left({ }^{\circ} \mathrm{C}\right) \\
\end{array}$} \\
\hline & $\begin{array}{c}\text { Monomer } \\
\text { System }\end{array}$ & $\begin{array}{l}\text { Initiator } \\
\text { /catalyst }\end{array}$ & $\begin{array}{c}\text { Water } \\
\text { (g) }\end{array}$ & $\begin{array}{c}\text { Stabiliser } \\
\text { system }\end{array}$ & \\
\hline $\mathrm{CNSL}[12] \mathrm{S}_{\mathrm{g}} \mathrm{P}$ & $\begin{array}{l}\mathrm{CNSL}=10.0 \mathrm{~g} \\
\text { formalin }=5 \mathrm{ml}\end{array}$ & $\begin{array}{l}7 \% \mathrm{NaOH} \\
=2 \mathrm{ml}\end{array}$ & 600 & $\begin{array}{l}\mathrm{Mg}(\mathrm{OH})_{2}=1 \mathrm{~g} \\
\mathrm{Ca}_{3}\left(\mathrm{PO}_{4}\right)_{2}=1 \mathrm{~g}\end{array}$ & 30 \\
\hline $\mathrm{CDN}[17] \mathrm{C}_{\mathrm{g}} \mathrm{P}$ & cardanol $=5 \mathrm{~g}$ & $\begin{array}{l}\left(\mathrm{CH}_{3}\right)_{2} \mathrm{SO}_{4} \\
\quad=3 \mathrm{ml}\end{array}$ & 650 & $\begin{array}{l}\mathrm{Mg}(\mathrm{OH})_{2}=0.5 \mathrm{~g} \\
\mathrm{Ca}_{3}\left(\mathrm{PO}_{4}\right)_{2}=0.5 \mathrm{~g}\end{array}$ & 50 \\
\hline $\mathrm{CDN}[18] \mathrm{C}_{\mathrm{g}} \mathrm{P}$ & cardanol $=5 \mathrm{~g}$ & B.P $=0.5 \mathrm{~g}$ & 350 & Starch $=2 \mathrm{~g}$ & 30 \\
\hline $\mathrm{SCDN}[21] \mathrm{C}_{\mathrm{g}} \mathrm{P}$ & $\begin{array}{l}\text { styrene }=2.5 \mathrm{~g} \\
\text { cardanol }=2.5 \mathrm{~g}\end{array}$ & B.P $=0.1 \mathrm{~g}$ & 300 & $\begin{array}{l}\mathrm{Ca}_{3}\left(\mathrm{PO}_{4}\right)_{2}=2 \mathrm{~g} \\
\mathrm{Mg}(\mathrm{OH})_{2}=1 \mathrm{~g} \\
\mathrm{Al}(\mathrm{OH})_{3}=0.5 \mathrm{~g}\end{array}$ & 40 \\
\hline $\mathrm{CNSL}[23] \mathrm{C}_{\mathrm{g}} \mathrm{P}$ & $\mathrm{CNSL}=10 \mathrm{~g}$ & B.P $=0.15 \mathrm{~g}$ & 400 & $\begin{array}{c}\text { Starch }=2 \mathrm{~g} \\
\mathrm{Ca}_{3}\left(\mathrm{PO}_{4}\right)_{2}=0.5 \mathrm{~g}\end{array}$ & 55 \\
\hline $\mathrm{CNSL}[27] \mathrm{S}_{\mathrm{g}} \mathrm{P}$ & $\begin{array}{l}\mathrm{CNSL}=5 \mathrm{~g} \\
\text { formalin }=3 \mathrm{ml}\end{array}$ & $\begin{array}{l}7 \% \mathrm{NaOH} \\
=2 \mathrm{ml}\end{array}$ & 600 & $\mathrm{Mg}(\mathrm{OH})_{2}=1.5 \mathrm{~g}$ & 50 \\
\hline $\mathrm{CNSL}[29] \mathrm{S}_{\mathrm{g}} \mathrm{P}$ & $\begin{array}{l}\mathrm{CNSL}=10 \mathrm{~g} \\
\text { formalin }=5 \mathrm{ml}\end{array}$ & $\begin{array}{l}7 \% \mathrm{NaOH} \\
=3 \mathrm{ml}\end{array}$ & 650 & $\begin{array}{c}\mathrm{Ca}_{3}\left(\mathrm{PO}_{4}\right)_{2}=2 \mathrm{~g} \\
\mathrm{Mg}(\mathrm{OH})_{2}=1.5 \mathrm{~g} \\
\mathrm{Al}(\mathrm{OH})_{3}=0.5 \mathrm{~g}\end{array}$ & 45 \\
\hline $\mathrm{CNSL}[37] \mathrm{C}_{\mathrm{g}} \mathrm{P}$ & $\mathrm{CNSL}=12.7 \mathrm{~g}$ & B.P $=2.53 \mathrm{~g}$ & 500 & $\begin{array}{c}\mathrm{Ca}_{3}\left(\mathrm{PO}_{4}\right)_{2}=2 \mathrm{~g} \\
\mathrm{Mg}(\mathrm{OH})_{2}=1 \mathrm{~g} \\
\mathrm{Starch}=1.5 \mathrm{~g}\end{array}$ & 60 \\
\hline $\mathrm{CDN}[38] \mathrm{C}_{\mathrm{g}} \mathrm{P}$ & cardanol $=5.8 \mathrm{~g}$ & B.P $=0.43 \mathrm{~g}$ & 400 & $\begin{array}{c}\mathrm{Ca}_{3}\left(\mathrm{PO}_{4}\right)_{2}=2.5 \mathrm{~g} \\
\mathrm{Al}(\mathrm{OH})_{3}=1 \mathrm{~g} \\
\mathrm{Starch}=1.3 \mathrm{~g}\end{array}$ & 60 \\
\hline $\mathrm{CNSL}[40] \mathrm{S}_{\mathrm{g}} \mathrm{P}$ & $\begin{array}{l}\mathrm{CNSL}=10 \mathrm{~g} \\
\text { formalin }=10 \mathrm{ml}\end{array}$ & $\begin{array}{l}7 \% \mathrm{NaOH} \\
=3 \mathrm{ml}\end{array}$ & 600 & $\begin{array}{l}\mathrm{Mg}(\mathrm{OH})_{2}=1 \mathrm{~g} \\
\mathrm{BaSO}_{4}=0.5 \mathrm{~g}\end{array}$ & 55 \\
\hline
\end{tabular}

B.P = Benzoyl peroxide; in each recipe $2-3 \mathrm{ml}$ of dodecyl alcohol was added as a porogen

During SPP preparation, it was noted that use of large volume of monomer in the recipe relative to the volume of the aqueous phase changed the polymerization course to bulk polymerization. In such situations, (recipes no. 6, 7, 8, 11 and 20, - not shown in Table 1), the agitation mechanism could not effectively disperse the monomer phase into droplets and the stabilizer system consequently failed to prevent coalescence of the monomer phase.

Most of the unsuccessful recipes were those involving chain-growth mechanism, i.e., those in which benzoyl peroxide was used as the initiator. It was observed that with the amount of benzoyl peroxide less than about $1.5 \%$ the weight of the monomer, polymerization could not proceed for sufficient period of time thereby leading to coagulation and failure to SPP formation.

\section{Chemical Stability of SPP}

The results of treatment of SPP with reactive agents are given in Table 2. The results indicate that SPP have good resistance against chemical attack of many common solvents. When treated with concentrated sodium hydroxide solution and most of organic solvents, the particles remained physically stable and maintained mechanical integrity. Most of the solvents, however, extracted color from the polymer particles but the particles remained undestroyed. The treatment with concentrated sulphuric acid, on the other hand, seemed to dehydrate and carbonize the particles. Heating the particles to $120-150{ }^{\circ} \mathrm{C}$, like treatment with mineral acids, resulted in improved hardness of the 
particles. The fact that the particles were largely unaffected by harsh chemical environment and remained stable, suggests the plausibility of using SSP for catalyst supports and other surface-active applications.

Table 2: $\quad$ The effect of treatment of SPP with various chemical agents

\begin{tabular}{|c|c|c|c|c|c|}
\hline Reagents & CNSL[12] $S_{g} P$ & CNSL[29]S $S_{g} P$ & CNSL[23] $C_{g} P$ & $\begin{array}{l}\text { CNSL }[37] \mathrm{C}_{\mathrm{g}} \mathbf{P} \\
\text { dried }-\mathbf{8 0}^{\circ} \mathrm{C}\end{array}$ & $\begin{array}{l}\text { CNSL[37] } \mathrm{C}_{\mathrm{g}} \mathrm{P} \\
\text { dried }-140^{\circ} \mathrm{C}\end{array}$ \\
\hline Methanol & Bleached & No effect & No effect & Corroded & No effect \\
\hline Ethanol & No effect & No effect & No effect & No effect & \\
\hline Chloroform & $\begin{array}{l}\text { Bleached, } \\
\text { Corroded }\end{array}$ & Swollen & No effect & Corroded & No effect \\
\hline Ethyl acetate & Swollen & Swollen & No effect & No effect & No effect \\
\hline n-Hexane & No effect & Swollen & No effect & Corroded & No effect \\
\hline $97 \% \mathrm{H}_{2} \mathrm{SO}_{4}$ & $\begin{array}{c}\text { Carbonized, } \\
\text { Hardened }\end{array}$ & $\begin{array}{c}\text { Carbonized, } \\
\text { Hardened }\end{array}$ & No effect & $\begin{array}{c}\text { Carbonized, } \\
\text { Hardened }\end{array}$ & No effect \\
\hline dil $\mathrm{H}_{2} \mathrm{SO}_{4}$ & No effect & No effect & No effect & No effect & No effect \\
\hline conc $\mathrm{HNO}_{3}$ & $\begin{array}{l}\text { Bleached, } \\
\text { Hardened }\end{array}$ & $\begin{array}{l}\text { Bleached, } \\
\text { Hardened }\end{array}$ & No effect & Bleached & No effect \\
\hline $5 \mathrm{M} \mathrm{NaOH}$ & No effect & No effect & No effect & Swollen & No effect \\
\hline
\end{tabular}

\section{The Average Particle Size of SPP}

The SEM picture of the SPP obtained from recipe CNSL[40] $\mathrm{S}_{\mathrm{g}} \mathrm{P}$ is shown in Figure 1. Apparently the particles obtained have narrow size distribution. A highly magnified micrograph of a single polymer particle (Figure 2) enables a closer examination of the morphology of the particles. From figure 2, the spherical shape of the particle is evident.
The particle seems to have smooth surface with craters. These craters are probably due to the small stabilizer particles that are lightly adsorbed on the polymer particle surface during the polymerization reaction. After the reaction these stabilizer particles are washed off but leave their imprints on the surface in the form of craters.

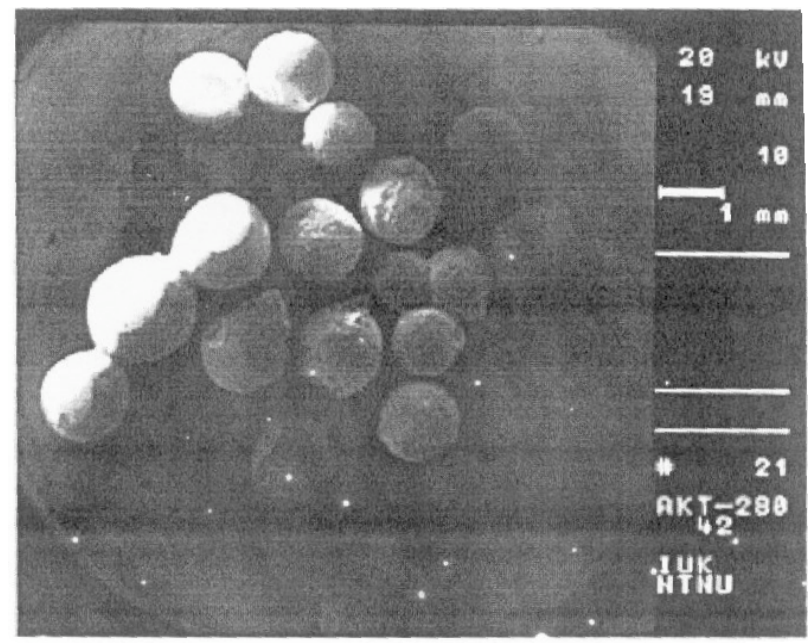

Figure 1: Spherical polymer particles from CNSL. 


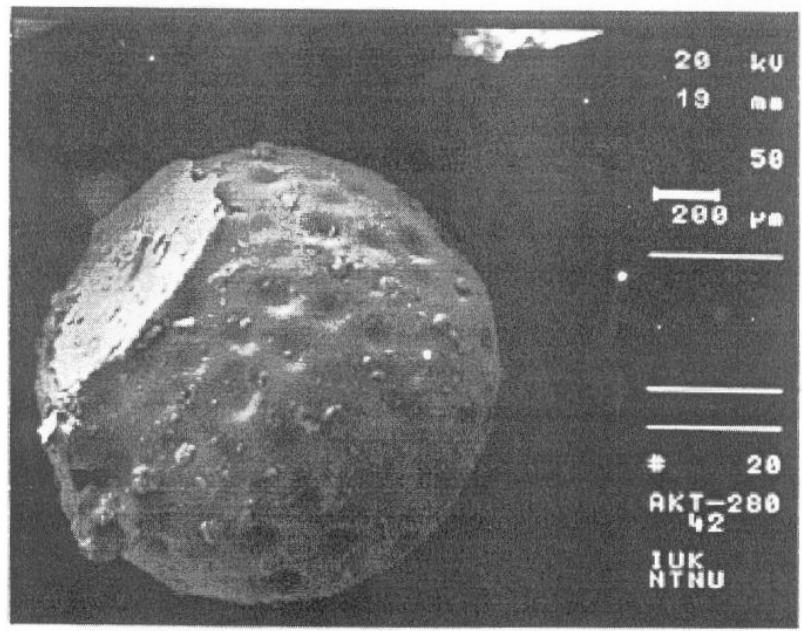

Figure 2: A magnified polymer particle from CNSL

Typical results of particle size analysis are depicted in Figure 3, which gives the size distribution for SPP from recipe no. CNSL[12] $\mathrm{S}_{\mathrm{g}} \mathrm{P}$. The modal size and the average size of the particles from this recipe are $0.7 \mathrm{~mm}$ and $0.9 \mathrm{~mm}$, respectively. The sizes of the particles obtained from other recipes are summarized in Table 3.

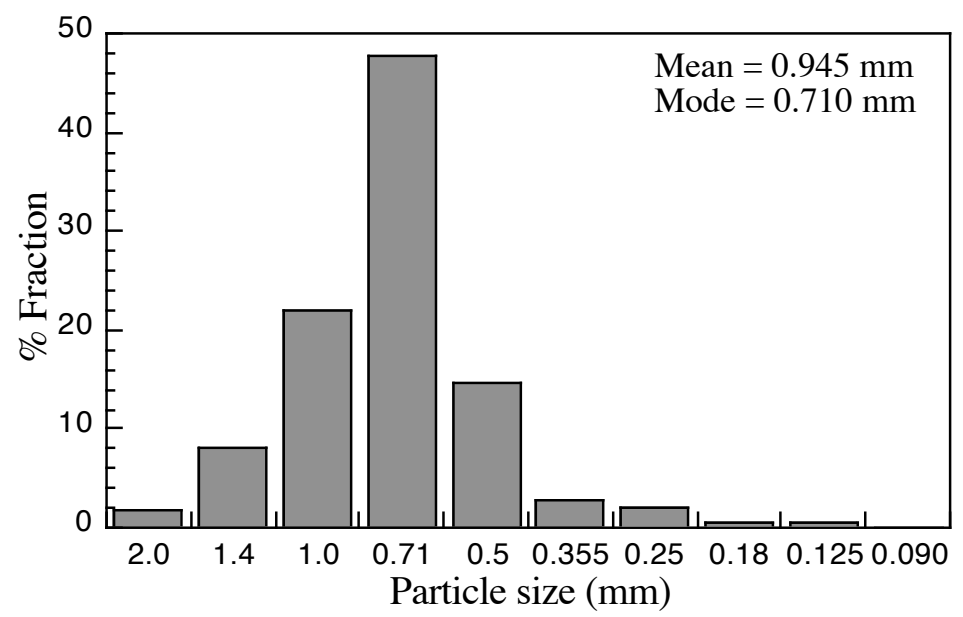

Figure3: Size distribution for spherical polymer particles obtained from recipe no. CNSL[12] $\mathrm{S}_{\mathrm{g}} \mathrm{P}$.

The average particle sizes of polymer beads prepared by suspension polymerization are known to depend on both the strength of agitation (Ahmed 1984, Brooks 1990) and the nature and concentration of stabilizers employed (Landall 1982, Wright 1985). In this case a constant agitation speed was maintained. However, the effect of concentration of the stabilizer on the average particle size is apparent. The average particle 
sizes decreased with increasing amount of stabilizers in the recipes. This is the expected observation since the more the stabilizer the larger the surface area that can be stabilized. By varying the concentrations of stabilizers in different recipes, SPP particles with average sizes ranging from 0.4 to $1.6 \mathrm{~mm}$, with a maximum and minimum sizes of 2.0 and $0.1 \mathrm{~mm}$, respectively, could be obtained.

Table 3: $\quad$ A summary of particle size analysis of SPP.

\begin{tabular}{ccc}
\hline & \multicolumn{2}{c}{ Size (diameter) of SPP } \\
\cline { 2 - 3 } Recipe no. & Modal size (mm) & Average size (mm) \\
\hline CNSL[12] $\mathrm{S}_{\mathrm{g}} \mathrm{P}$ & 0.7 & 0.95 \\
CDN[17]C $\mathrm{g}_{\mathrm{g}} \mathrm{P}$ & 1.0 & 0.91 \\
CDN[18]C $\mathrm{C}$ & 0.5 & 0.73 \\
CNSL[23]C $\mathrm{C}_{\mathrm{g}} \mathrm{P}$ & 0.7 & 0.64 \\
CNSL[27] $\mathrm{S} P$ & 2.0 & 1.47 \\
CNSL[29]S $\mathrm{S}$ & 0.25 & 0.42 \\
CNSL[37]C $\mathrm{C}_{\mathrm{g}} \mathrm{P}$ & 1.6 & 1.2 \\
CDN[38]C $\mathrm{g} P$ & 0.25 & 0.39 \\
CNSL[40] $\mathrm{S}_{\mathrm{g}} \mathrm{P}$ & 1.2 & 1.19 \\
\hline
\end{tabular}

\section{Particles Surface Area}

From Table 4, it can be seen that the beads prepared without a porogen have smaller surface areas than those prepared with the porogen. For example, in recipe 5 and 29 the surface area changed from 1.3906 (recipe 5) to $15.676 \mathrm{~m}^{2} \mathrm{~g}^{-1}$ (recipe 29). It appears that the increase in surface area is caused by the added porogen in a manner that still remains equivocal. Indeed this is evidence of the porogen (pore-generating agent) at work, i.e., developing the pore system of the beads and thus affecting their internal surface area. Furthermore, it is noted that beads prepared from CDN have larger surface areas than beads prepared from CNSL (table 2, recipe 18 and 23). Generally it is noted that beads prepared via a chain-growth polymerization mechanism had larger surface areas than those prepared by step-growth polymerization. However, further work is needed to establish and account for the observed differences.

Table 4: $\quad$ Surface area values for some of the SPP prepared.

\begin{tabular}{|c|c|c|c|c|}
\hline $\begin{array}{c}\text { Particle } \\
\text { Recipe code }\end{array}$ & $\begin{array}{c}\text { Weight of sample } \\
\text { (g) }\end{array}$ & $\begin{array}{l}\text { Degassing Temp. } \\
\left({ }^{\circ} \mathrm{C}\right)\end{array}$ & $\begin{array}{c}\text { Degassing Time } \\
\text { (h) }\end{array}$ & $\begin{array}{c}\mathrm{S}_{\mathrm{BET}} \\
\left(\mathrm{m}^{2} / \mathrm{g}\right)\end{array}$ \\
\hline CNSL[5] $\mathrm{S}_{\mathrm{g}} \mathrm{P}$ & 0.046 & 200 & 12 & 1.4 \\
\hline $\mathrm{CDN}[17] \mathrm{C}_{\mathrm{g}} \mathrm{P}$ & 0.061 & 250 & 18 & 4.6 \\
\hline $\mathrm{CDN}[18] \mathrm{C}_{\mathrm{g}} \mathrm{P}$ & 0.085 & 250 & 12 & 260 \\
\hline $\mathrm{CNSL}[23] \mathrm{C}_{\mathrm{g}} \mathrm{P}$ & 0.050 & 250 & 12 & 83 \\
\hline $\mathrm{CNSL}[29] \mathrm{S}_{\mathrm{g}}^{\circ} \mathrm{P}$ & 0.098 & 250 & 18 & 16 \\
\hline CNSL[38]C $\mathrm{C}_{\mathrm{g}} \mathrm{P}$ & 0.052 & 200 & 18 & 110 \\
\hline
\end{tabular}

\section{Adsorption Capacity}

The adsorption capacity of the SPP was determined by the batch technique using $\mathrm{Na}^{+}$ and $\mathrm{Ca}^{2+}$ adsorbates. The results were interpreted by the Langmuir equation whose plots are shown in Figures 4 and 5. The plots show the amounts of adsorbate adsorbed in $\mathrm{mg} / \mathrm{g}$ versus the electrolyte concentration. At the concentration of about $50 \mathrm{mg} / \mathrm{dm}^{3}$ of $\mathrm{Na}^{+}, \mathrm{CDN}[18] \mathrm{CgP}$ adsorbed $7.43 \mathrm{mg} / \mathrm{g}$ and $\mathrm{CDN}$ [17]CgP adsorbed 2.49 $\mathrm{mg} / \mathrm{g}$. But CNSL[5]SgP adsorbed 8.34 
$\mathrm{mg} / \mathrm{g}$ of $\mathrm{Ca}^{2+}$ whereas $\mathrm{CDN}[38] \mathrm{CgP}$ adsorbed $26.87 \mathrm{mg} / \mathrm{g}$ of $\mathrm{Ca}^{2+}$. This implies that the adsorption increased with the increase in surface area. According to the results, the adsorption characteristics of the SPP conform to the Langmuir adsorption isotherm (Langmuir 1916) with maximum saturation capacity of about $9.0 \mathrm{mg} / \mathrm{g}$ and $44.2 \mathrm{mg} / \mathrm{gram}$ for $\mathrm{Na}^{+}$and $\mathrm{Ca}^{2+}$, ions respectively. The higher affinities of CNSL resins for bivalent cations compared to univalent cations at low concentrations have been reported previously (Gedam et al. 1986).

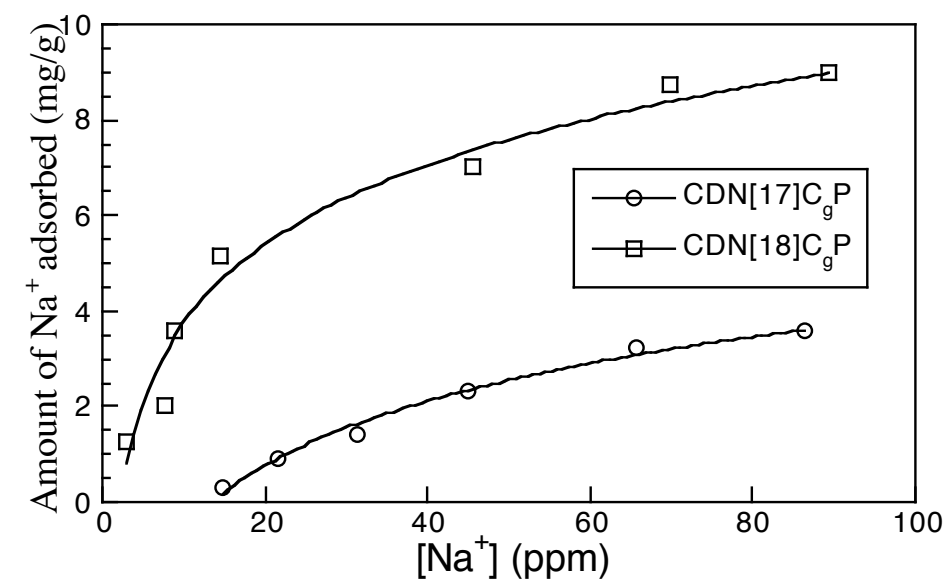

Figure 4: Adsorption of $\mathrm{Na}^{+}$by SPP.

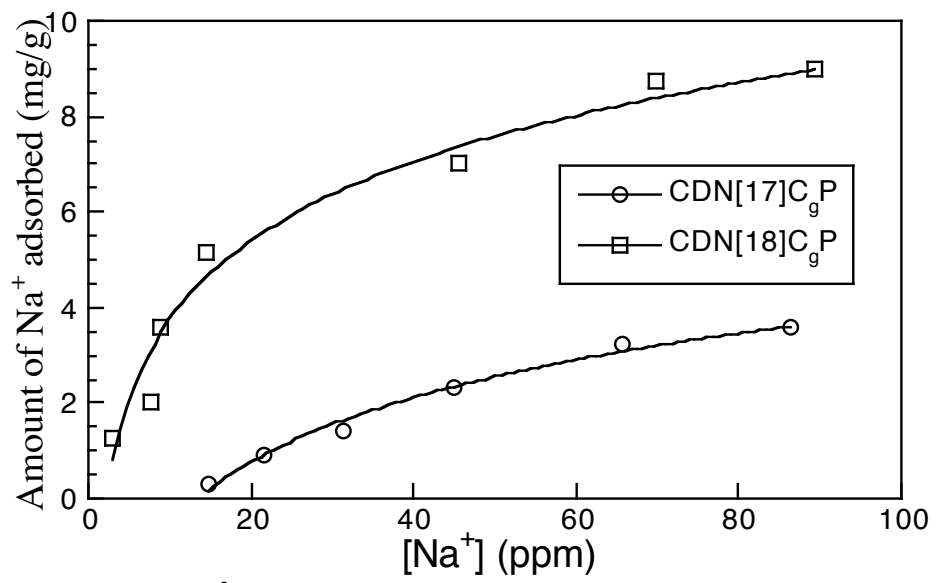

Figure 5: Adsorption of $\mathrm{Ca}^{2+}$ by SPP.

\section{CONCLUSION}

This study establishes that it is possible to prepare spherical polymeric particles from CNSL and its distillate, cardanol, by suspension polymerization. The strong influence of amount of stabilizers on the size of the polymer particles is observed. It is further observed that the particles formed can be used for adsorbing cations, particularly the particles prepared from cardanol by 
addition polymerization. Further study is in progress to establish the effect of different porogens, at various concentrations, to the surface area of the particles. The particles themselves are being investigated for their application as precursors of functionalized catalysts utilizing the surface hydroxyl groups.

\section{ACKNOWLEDGEMENT}

We are grateful to the Norwegian Agency for Development Cooperation (NORAD), through the Chemistry Department, University of Dar es Salaam for financing this project.

\section{REFERENCES}

Ahmed SM 1984 Effect of agitation and the nature of protective colloid on particle size during suspension polymerization J. Disp. Sci. Technol., 5: 421-432.

Anand LC 1978 CNSL based polymers and their applications Paintindia 28: 13 33.

Anand LC 1981 Some reaction of CNSL and its constituents, J. Chem. \& Petrochem., 12(5): 1.

Arshady R 1992 Suspension, emulsion and dispersion polymerization: A methodological survey Colloid. Polym. Sci. 270: 717 - 732 .

Bhunia HP, Jana RN, Basak A, Lenka S and Nando GB 1998 Synthesis of polyurethane from Cashew Nut Shell Liquid (CNSL), a renewable resource J. Polym. Sci. Part A: Polym. Chem. 36: 391 - 400.

Brooks BW 1990 Basic aspects and recent development in suspension polymerization Makromol. Chem., Macromol. Symp. 35/36: 121-140.

Brunauer S, Emmett PH and Teller E 1938 Adsorption of gases in multimolecular layers. J. Am. Chem. Soc., 60: $309-319$.
Gedam PH and Sampathkumaran PS 1986 Cashew Nut Shell Liquid: extraction, chemistry and applications Prog. Org. Coatings, 14: 115 -157.

Heal GR and Mkayula LL 1988 The preparation of palladium metal catalysts supported on carbon: Part I - Selection and treatment of carbons Carbon, 26: 803 - 813 .

Hodge P and Sherrington DC 1980 Polymer-Supported reactions in organic synthesis, John Wiley and Sons.

Landall LM (Hercules Inc.) 1982 Use of hydrophobically modified water soluble polymers in suspension polymerization. US. Pat. 4,352,916.

Langmuir I 1916 Kinetic model of the adsorption process J. Amer. Chem. Soc. 38: 222.

Mark HF, Bikales NM, Overberger CG, and Menges G 1989 Suspension polymerization Encyclopedia of Polymer Science and Engineering, $2^{\text {nd }}$ ed., Wiley; 16: 443 - 471.

Mwaikambo LY and Ansell MP (2001) Cure characteristics of alkali catalysed cashew nut shell liquid-formaldehyde resins. $J$. Materials Sci. 36: 3693 - 3698.

Tyman JHP 1975 Long-chain phenols: V. Gas chromatographic analysis of cashew nut shell liquid (anacardium occidentale) J. Chromatogr. 111: $285-292$.

Rolls W, Svec F and Frechet JMJ 1990 Design and synthesis of macroporous polymeric separation media based on substituted phenols, Polymer, 31: $165-174$.

Wright HA 1985 (Atlantic Richfield Co.) Process for bead size control in vinyl aromatic suspension polymerization using sodium polystyrenesulphonate. US. Pat. 4,500,692. 
Mkayula et al. - Preparation of spherical polymeric particles ... 